\title{
The ability of squirrel monkeys to solve randomly presented string problems
}

DOUGLAS D. FIFE and MARVIN KAMBACK, University of South Dakota, Vermillion, S. Dak. 57069

Patterned string problems were presented in a random order to three squirrel monkeys. The performance of $S s$ indicated that a response-position preference had been established, which was based on the location of the reward. Squirrel monkeys were found to be inferior in solution of string problems when compared to other primate species. The relative difficulty of specific string problems that had been established for the rhesus monkey appeared to be different for the squirrel monkey.

Comparative studies have found that rock squirrels (King \& Witt, 1966) learn problems involving parallel strings but ultimately fail on intermixed crossed and pseudocrossed patterns. Raccoons (Michels, Pustek, \& Johnson, 1961), however, are able to solve intermixed crossed and pseudocrossed patterns following extensive practice on a series of these problems. Differences in ability to solve string problems were not found (Harlow \& Settlage, 1934) among several Old World monkeys (baboon, mangabey, mandrill, mona, rhesus, pigtail, and java) and New World monkeys (cebus and spider), each of which appeared to be superior to nonprimate species. Higher apes, such as orang-utans (Fischer \& Kitchner, 1965), lowland gorillas (Riesen, Greenberg, Granston, \& Fantz, 1953), and adult chimpanzees (Finch, 1941), have achieved the highest level of proficiency on patterned string problems.

Primates have usually been tested by advancing $S$ along a series of patterns, which have been judged by Es as being progressively difficult. Davis \& McDowell (1953), however, presented string problems to rhesus monkeys in a random order. Results of their study indicated that the judgments of past Es appeared to be correct concerning the relative difficulty of specific string patterns.

The present experiment was designed to assess the ability of the squirrel monkey, a New World species, to solve string problems presented randomly. It was anticipated that this method of testing would indicate if the correspondence between judged and demonstrated difficulty of specific patterns which was found to exist for the rhesus would also hold for the squirrel monkey. During preparation of the present manuscript, Cha \& King (1969) published the results of an experiment on the learning of string patterns by squirrel monkeys. The specific string patterns and the method of presentation used by Cha \& King (1969) differed from that of the present study in a manner that encouraged a comparison of the results of the two experiments.

\section{SUBJECTS}

Two female and one male squirrel monkey (Saimiri sciureus) were tested. Each $S$ had been exposed to identical taming and previous testing procedures and was approximately 3 years of age at the start of the experiment. Housing of Ss was on an individual basis. Food reward consisted of a small piece of apple. No deprivation schedule was imposed.

\section{APPARATUS}

A test tray consisted of a wooden board, $24 \times 17$ in., painted neutral gray. Screw eyes were placed at 1 -in. intervals along the longer side of the test tray, which was located nearest to the animal. The "strings" were constructed of brass plumber's chain with a 1 -in. blunt steel pin at one end and a snap at the other. The snap served to anchor the chain to a screw eye on the test tray. String problems consisted of the six patterns adopted by Davis \& McDowell (1953) from the series used by Harlow \& Settlage (1934).

A wooden platform supported the test tray and could be suspended at the front of the home cage by means of a hook. Wooden tracks were provided on the platform to enable the test tray to be moved toward and away from the home cage. An opaque screen was placed in a supporting frame at one end of the platform, within which it could be raised and lowered between the test tray and the home cage.

\section{PROCEDURE}

All testing was conducted from the home cage. A pretraining criterion of five successive pulls of a single baited string was imposed on each $S$ before testing was begun. Each problem was presented 75 times to each $S$ tested. A testing session consisted of one presentation of all six problems in a random sequence. The two asymmetrical patterns were alternated randomly with their mirror images. The string in each pattern to be baited was randomly determined.

Testing was conducted in the following manner on each trial: (1) The previous pattern was cleared and the appropriate new pattern arranged and baited by skewering the reward on the pin at the end of the correct string; (2) the opaque screen was raised, and the test tray was immediately pushed forward; (3) S was allowed to respond, after which the tray was pulled out of S's reach; and (4) the opaque screen was lowered and S's response was scored. A response was scored as correct only if $S$ grasped the baited string first and pulled the reward into the home cage. A noncorrection procedure was adopted throughout all sessions.

\section{RESULTS}

An 0.05 level of significance was adopted for all statistical analysis, al though the numerical probability of results exceeding this level of significance was also presented.

A chi-square test (Siegel, 1956) was used to compare the combined responses of Ss on each problem with every remaining problem. Results of these paired comparisons are presented in Table 1 . The most striking differences involved comparisons of the cross (1) and four crossing (4) strings patterns with the remaining four problems.

The raw data obtained by Davis \& McDowell (1953) was available for the 16 rhesus monkeys tested on the same problems. A Mann-Whitney U test (Siegel, 1956) indicated that the number of correct choices by each of the rhesus monkeys was significantly higher than the number of correct choices made by each of the squirrel monkeys $(U=0, p<0.01$, one-tailed). The percentage of correct responses on each problem made by thesus and by squirrel monkeys are presented in Fig. 1. These data show that the squirrel monkeys performed better on the double crossing (5) and pseudocross (6) string problems. The total number of correct responses made by each squirrel monkey

Table 1

Paired Comparisons of String Patterns

\begin{tabular}{cc}
\hline $\begin{array}{c}\text { Pattern } \\
\text { Comparisons }\end{array}$ & \multicolumn{1}{c}{$\mathrm{Chi}^{2}$} \\
\hline 1 vs 2 & $8.07^{* *}$ \\
1 vs 3 & $4.99^{*}$ \\
1 vs 4 & 0.55 \\
1 vs 5 & $13.41^{* *}$ \\
1 vs 6 & $22.28^{* *}$ \\
2 vs 3 & 0.34 \\
2 vs 4 & $38.92^{* *}$ \\
2 vs 5 & 0.65 \\
2 vs 6 & $3.66^{*}$ \\
3 vs 4 & $32.16^{* *}$ \\
3 vs 5 & 2.02 \\
3 vs 6 & $6.34^{*}$ \\
4 vs 5 & $49.00^{* *}$ \\
4 vs 6 & $63.53^{* *}$ \\
5 vs 6 & 1.15 \\
\hline$p<.05$ & $* 0<1$
\end{tabular}


and each rhesus monkey on every pattern was compared with Mann-Whitney U tests. Significant differences were found between the performance of rhesus and squirrel monkeys, with the rhesus performing better on the cross (1) $(U=0, p<0.01$, one-tailed) and four crossing (4) $(U=1$, $\mathrm{p}<0.01$, one-tailed) strings problems.

\section{DISCUSSION}

Inspection of the data suggests that it should not be concluded that all problems were solved by tracing the paths of the strings. Data presented in Table 1 and Fig. 1 show that performance was definitely poorest on the cross (1) and four crossing (4) strings patterns. Reward on these problems was located some distance to the right or left of a hypothetical line extending across the tray from the position at which the string could be grasped. In the case of the angle cross (3), double crossing (5), and pseudocross (6) string patterns, reward was located at a position directly across the tray from the portion of the string within S's reach. It appears that squirrel monkeys mastered the technique of pulling the string whose origin was in front of the position of the reward, rather than by visual tracing of the individual strings. Reward could be obtained by this method on three of the five problems that involved crossing strings or a pseudocross. Therefore, Ss had effectively maximized rewards if visual tracing was to be avoided. All squirrel monkeys, however, were observed to trace the strings on the box (2) string pattern in a number of cases and, occasionally, on other problems, especially after committing a series of errors. Visual tracing of the strings on the box (2) pattern could be accomplished quickly, while more time was required by the other patterns. This suggests that visual tracing of strings is not beyond the capacity of the squirrel monkey, but that observing techniques that require more than a momentary glance are abandoned in favor of responding by means of a response-position preference contingent upon the position of the reward.

Squirrel monkeys in the present study appeared to be superior to rock squirrels

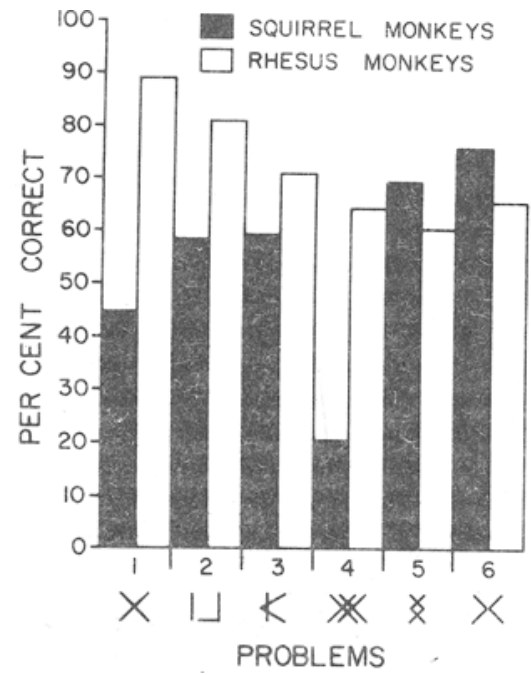

Fig. 1. Percentage of correct responses made by squirrel and rhesus monkeys on each string problem.

(King \& Witt, 1966), in which the same response-position preference was more dominant but inferior to raccoons (Michels, Pustek, \& Johnson, 1961), who overcame responding to position after extensive training on each problem. Performance was definitely inferior to species that usually do not adopt a simple position habit, such as several New World and Old World monkeys (Harlow \& Settlage, 1934), chimpanzees (Finch, 1941), gorillas (Riesen, Greenberg, Granston, \& Fantz, 1953), and orang-utans (Fischer \& Kitchner, 1965). Exact comparisons in the above cases are impossible because of differences in specific problems and methods of presentation.

Squirrel monkeys tested by Cha \& King (1969) adopted the same response-position preference. These investigators used a successive method of presentation, with the exception of one phase of their study, in which Ss learned either a cross or a pseudocross pattern, were then shifted to the other of these two patterns, and finally to an intermixed series of cross and pseudocross problems. This procedure demonstrated that squirrel monkeys can learn a position preference of pulling the string that is located farthest from the reward. Fewer errors were committed, however, in learning to pull the string anchored directly in front of the reward than in pulling the string located farthest from the reward.

The comparison of $\mathrm{Ss}$ in the present study to the rhesus monkeys tested by Davis \& McDowell (1953) indicated that the squirrel monkey is definitely inferior in solution of patterned string problems under the same testing procedure. Furthermore, the relative difficulty of specific problems (see Fig. 1) was not the same for both species. It may be concluded, then, that the correspondence between assumed and actual order of difficulty found by Davis \& McDowell (1953) for the rhesus does not apply for the squirrel monkey.

\section{REFERENCES}

CHA, J., \& KING, J, E. The learning of patterned strings problems by squirrel monkeys. Animal Behaviour, 1969, 17, 64-67.

DAVIS, R. T., \& MCDOWELL, A. A. Performance of monkeys on randomly presented string problems. Proceedings of the South Dakota Academy of Science, 1953, 32, 147-152.

FINCH, G. The solution of patterned strings problems by chimpanzees. Journal of Comparative \& Physiological Psychology, $1941,32,83-90$

FISCHER, G. J., \& KITCHNER, S. L. Comparative learning in young gorillas and orang-utans. Journal of Genetic Psychology, $1965,107,337-348$.

HARLOW, H. F., \& SETTLAGE, P. H. Comparative behavior of primates: VII. Capacity of monkeys to solve patterned strings tests. Journal of Comparative Psychology, $1934,18,423435$.

KING, J. E., \& WITT, E. D. The learning of patterned strings problems by rock squirrels. Psychonomic Science, 1966, 4, 319-320.

MICHELS, K. M., PUSTEK, JR., J. J., \& JOHNSON, JR., J. I. The solution of patterned strings problems by raccoons. Joumal of Comparative \& Physiological Psychology, $1961,54,439-441$.

RIESEN, A. H., GREENBERG, B., GRANSTON, A. H., \& FANTZ, R. L. Solutions of patterned strings problems by young gorillas. Journal of Comparative \& Physiological Psychology, 1953, 46, 19-22.

SIEGEL, S. Nonparametric statistics for the behavioral sciences. New York: MoGraw-Hill, 1956. 